\title{
Interpretasi Humanistik Kebahasaan: Upaya Kontekstualisasi Kaidah Bahasa Arab
}

\author{
Abd Aziz \\ Sekolah Tinggi Ilmu Tarbiyah (STIT) Al-Amin Kreo Tangerang \\ azizindunisi@stitalamin.ac.id
}

Saihu

Institut Perguruan Tinggi Ilmu Al-Quran (PTIQ) Jakarta

madesaihu@ptiq.ac.id

\begin{abstract}
This research concludes that language and humanity are inseparable needs, where language is a tool for thinking for humans. Language which is an expression of the meaning it contains and the ideas it captures come from the universality of universality, including humanity. This research uses descriptive analysis method, by concluding all the data presented in this study. Halliday as one of the basic arguments in writing this article also explained that the function of interactional language, where human interaction is intertwined, one of which is through language, in this context is Arabic. As language users, humans have the emotive and imaginative power to interpret what they hear, what they say, and what they see. When Arabic is released into the public sphere, the resulting meaning will have a contextual correlation, and this meaning also adjusts to the interpreter's conceptual reference. The meaning that is covered by the language rules is extracting humanistic values as a form of enthusiasm to contextualize language texts in a wider scope.
\end{abstract}

Keywords: Humanistic-interpretation, Arabic, contextual

\begin{abstract}
Abstrak
Penelitian ini menyimpulkan bahwa bahasa dan kemanusiaan adalah kebutuhan yang tak dapat dipisahkan, dimana bahasa sebagai alat berpikir bagi manusia. Bahasa yang merupakan ekspresi atas makna yang dikandungnya dan ide-ide yang ditangkapnya berasal dari universalitas kesemestaan, termasuk di dalamnya kemanusiaan. Penelitian ini menggunakan metode deskriptif analisis, dengan menyimpulkan segala data yang tersaji dalam penelitian ini. Halliday sebagai salah satu argumen dasar dalam penulisan artikel ini juga
\end{abstract}


menjelaskan bahwa fungsi bahasa yang interaksional, di mana interaksi manusia terjalin, salah satunya melalui bahasa, dalam konteks ini adalah bahasa Arab. Sebagai pengguna bahasa, manusia memiliki kekuatan emotif dan imajinatif untuk menafsirkan apa yang mereka dengar, apa yang mereka ucapkan, dan apa yang mereka lihat. Ketika bahasa Arab dilepaskan ke ruang publik, makna yang dihasilkan akan memiliki korelasi kontekstual, dan makna ini juga menyesuaikan dengan referensi konseptual penafsirnya. Makna yang tercakup dalam kaidah kebahasaan mengekstraksi nilai-nilai humanistik sebagai bentuk semangat untuk mengontekstualisasikan teks-teks bahasa dalam ruang lingkup yang lebih luas.

Kata kunci: interpretasi-humanistik, bahasa Arab, kontekstual

\section{Pendahuluan}

Manusia sebagai makhluk humanis meletakkan sesuatu dari cara pandang keberagamaan, dan secara otomatis setiap individu melibatkan dirinya dalam menyusun kemanusiaannya. Argumen ini kemudian akan membawa seseorang kepada suatu titik kesadaran bahwa betapa pentingnya bahasa bila terangkai untuk kemaslahatan manusia. Sebab, sekali lagi, manusia (humanis) adalah titik tolak dari keberagamaan itu sendiri. Bahasa diciptakan untuk manusia dan kemanusiaan. Sudah seyogianya bila bahasa harus dihadirkan untuk kemanusiaan. Penulis berupaya memberikan tawaran pandangan yang menjadi paradigma baru sehingga bahasa Arab mampu berperan di tengah arena publik modern. Cara pandang ini sebagai salah satu upaya keluar dari 'keterkungkungan' dalam memandang sesuatu.

Akal yang dimiliki manusia digunakan untuk berpikir, karena sebagai bentuk kesyukuran atas pemberian Tuhan kepada makhluk-Nya guna meraih kehidupan yang luhur dan berkualitas. Dengan budi manusia dapat menata kehidupannya yang teratur dan beradab. Akal-budi itulah yang melahirkan nilainilai kemanusiaan. Namun, manusia sering lupa terhadap anugerah akal-budi itu. Oleh karena itu, nilai-nilai kemanusiaan akan selalu diperjuangkan, agar setiap orang selalu hidup tidak seperti hewan atau binatang, ${ }^{1}$

Sesuai dengan prinsip berprikemanusiaan. Kata "pikir" (dalam bahasa Arab, fikr) biasanya adalah jenis kegiatan yang menemukan contoh substantif dalam kewujudan manusia, sehingga dimungkinkan untuk mengkarakterisasi menjadi suatu tanda yang membedakan dengan binatang. Jenis aktivitas tersebut yang memiliki kemampuan untuk berkomunikasi dengan orang lain, mampu mengantisipasi apa yang akan terjadi, dan mampu mengambil keputusan melakukan sesuatu berdasarkan pengalaman masa lalu dalam hidup. Yang menjadi garis bawah adalah bahwa dalam pikiran itu sendiri kita dapat

${ }^{1}$ Iip D. Yahya, Gus Dur: Berbeda itu Asyike (Yogyakarta: Kanisius, 2004). 
membedakan antara dua unsur: pertama representasi (madhmun al-fiker) atau isi pemikiran, kemudian aktivitas pemikiran (nasy'at al-fikr) itu sendiri dalam hal menjadi sebuah kegiatan (saya mewakili sesuatu oleh diri saya sendiri). ${ }^{2}$ Nilainilai kemanusiaan menyentuh luas berbagai bidang, seluas bidang kehidupan itu sendiri. ${ }^{3}$ Di samping itu pula, akal atau otak manusia jelas memiliki kemampuan untuk memiliki bahasa dalam pengertian umum, dan kemampuan ini mungkin dalam bentuk kemungkinan umum komunikasi danperformansi. ${ }^{4}$

Mahmud Syauqi Amin mengatakan bahwa pertumbuhan dan kematangan bahasa Arab dalam aspek suara (ashwat), bentuk-bentuk (shiyag), sistem kalimat, nilai nasionalisme kebangsaan yang meliputi universalitas dan inklusivitas di masa Jahili ketika itu telah bersiap untuk menerima lompatan besar pasca kemunculan Islam, sehingga berbagai lini kehidupan didalamnya akan berinteraksi dan berkembang seiring kemajuan budaya. ${ }^{5}$ Tak pelak, sejumlah pakar bahasa Arab diseluruh dunia tertarik untuk meneliti struktur dasar universal, yakni komposisi internal yang menyatu di tengah-tengah sebagian besar bahasa kemanusiaan. Alasan yang mendasari penelitian para pakar tersebut adalah suatu asumsi bahwa ada suatu bahasa kemanusiaan (lughah insaniyyah). Keberadaan suatu bahasa tunggal dapat disimpulkan oleh argumen bahwa bahasa apapun itu merupakan bahasa yang mengekspresikan makna, pikiran dan rasa. Sedangkan sebagian besar rasa, ide, dan makna adalah sesuatu yang universal bagi semua manusia dari berbagai ras danbahasa. ${ }^{6}$

Bahasa merupakan sistem ide dan budaya yang merupakan pintu masuk (madkhal) alamiah untuk menyelami nilai-nilai yang terakumulasi dalam masyarakat sepanjang sejarahnya, di samping sebagai sarana yang dipilih oleh manusia untuk berkomunikasi (tawashul). Inilah yang menyebabkan banyak orang tertarik pada sastra, seni, dan seluruh yang terjadi dalam cakrawala bahasa untuk menjadikannya sebagai penelitian, penulisan dan analisis,sehingga dengan begitu bahasa merupakan jendela untuk memahami otak manusia.

2 Slevan Oro, Gad Dishan, and Gamal Kologli, Falsafah al-Lughah (Beirut: Presses Universitaires de France, 2004). 305.

${ }^{3}$ Mohammad Monib and Islah Bahrawi, Islam \& Hak Asasi Manusia Dalam Pandangan Nurcholish Madjid (Jakarta: Gramedia Pustaka Utama, 2011). 35.

${ }^{4}$ Oro, Dishan, dan Kologli, Falsafah al-Lughah. 26. Pandangan Hymes yang mengatakan bahasa merupakan kemampuan menggunakan wacana. Sementara Chomsky menganggap kemampuan berbahasa ialah penguasaan aturan-aturan kebahasaan (competence) dan bagaimana menggunakannya (performance). Pandangan ini berimplikasi pada penguasaan gramatika lebih dulu sebelum menguasai kemampuan komunikasi (strukturalis). Ditambah pernyataan Nunan yang mengemukakan bahwa kaum strukturalis menganggap belajar bahasa ialah mempelajari kaidah atau sistem bahasa yang diantaranya meliputi struktur kata, struktur kalimat, kosakata, makna kata/kalimat, ejaan, dan lafal. Lihat CJ Richards and ST Rodgers, Approaches and Methods in Language Teaching (Cambridge: Cambridge University Press, 2001).

${ }^{5}$ Islam Kotob, Majallab Majma’ al-Lughah al-'Arabiyyah (Kairo: IslamKotob, 2003). 62.

${ }^{6}$ Muhammad 'Ali Al-Khuli, Qawa'id Tahwiliyyah li al-Lughah al-'Arabiyyah (Yordan: Dar alFalah, 1999). 13. 
Bidang penelitian linguistik membutuhkan pandangan baru terhadap bahasa yang dapat dimanfaatkan dari teori-teori lama dan kritiknya, serta memerlukan cara baru dalam menginteraksikan dengan glosari di dalamnya, sehingga mampu beradaptasi dengan lingkungan baru yang sudah ada. ${ }^{7}$ Ketika kembali kepada pendekatan estetik dalam bahasa Arab, kita menemukan lafallafal Arab sepanjang sejarahnya yang panjang dicirikan oleh keluwesan (murunab), kelancaran (salasah) dan mudah penggunaannya (subulah al-isti'mah).

Itulah kenapa bahasa adalah pola sinyal yang ada di masyarakat. Bahasa merupakan salah satu sarana komunikasi dan pemahaman yang paling penting antara individu dan kelompok, sehingga menghasilkan suatu bentuk fenomena yang kompleks, memunculkan berbagai warna penelitian dan studi. ${ }^{8}$

Penjelasan ini lebih mengait dengan benang merahnya bila memperhatikan keterangan Halliday sebagaimana dikutip Imroatus Solikhah, dimana fungsi bahasa dalam komunikasi, meliputi: (1) Fungsi instrumental: menggunakan bahasa untuk memperoleh sesuatu, (2) Fungsi regulatori: menggunakan bahasa untuk mengontrol perilaku orang lain, (3) Fungsi interaksional: menggunakan bahasa untuk berinteraksi dengan orang lain, (4) Fungsi personal: menggunakan bahasa untuk mengungkapkan perasaan dan makna, (5) Fungsi heuristik: menggunakan bahasa untuk belajar dan menemukan makna, (6) Fungsi imajinatif: menggunakan bahasa untuk menciptakan dunia imajinasi, dan (7) Fungsi representasional: menggunakan bahasa untukmenyampaikan informasi.

Penelitian ini menggunakan studi kepustakaan (library research), yang bersifat eksploratif dengan melihat fenomena kemanusiaan yang kemudian dihubungkan dengan pemaknaan terhadap kaidah kebahasaan Arab. Esensi suatu kaidah kebahasaan dikohesikan dengan pemaknaan eksistensi masyarakat dalam konteks humanistik menjadi titik tolak pembahasan ini.

\footnotetext{
7 'Umar Dzhahir, Ta'ammulat fi Falsafah al-Lughab; Khushusiyyah al-Lughah al-'Arabiyyah wa Imkanatuba (Beirut: Dar al-Rafidhain, 2008). 13.

${ }^{8}$ Musthafa Al-Masmudi, al-Nidzham al-'Alami al-Jadid (Kuwait: Silsilah 'Alam al-Ma'rifah, 1985). 209. Dalam konteks studi bahasa, Luther terus terang mengakui ketergantungannya pada karya-karya linguistik dan historis dari para tokoh humanis, dan secara khusus, pada teks Perjanjian Baru berbahasa Yunani yang disusun dan diterbitkan oleh Erasmus. Para wakil gerakan humanisme dan reformasi ini memiliki tujuan yang sama ketika mereka memulai pencarian atas teks Kitab Suci yang Asli dan atas penafsiran yang akurat secara historis. Para humanis telah lama dikenal sebagai ahli tata bahasa dan orator profesional, para penggerak reformasi tenggelam dalam studi bahasa dan kritik teks, yakni bidang-bidang khas para humanis, supaya dapat memberi dasar filologis pada pandangan teologis mereka. Lihat Thomas Hidya Tjaya, Humanisme dan Skolastisisme, Sebuah Debat (Yogyakarta: Kanisius, 2004). 82. Dengan begitu, sikap humanistik dapat menerjemahkan pandangan-pandangan teologi menjadi perlakuan yang memesona dan menebarkan keluhuran.

${ }^{9}$ Imroatus Solikhah, "Paradigma Baru Pembelajaran Bahasa dan Resistensi Masyarakat Terhadap Perubahan,” Cendekia 8, no. 2 (October 2014). 159.
} 
Pembahasan yang pernah dilakukan dan memiliki keterkaitan dengan bahasa dan kemanusiaan, antara lain: pertama, Antropologi Al-Quran karya Baidhowi tahun 2009. Penulisnya menggabungkan bahasa dengan berbagai persoalan kemanusiaan serta kemasyarakatan. Yang disinggung antaranya; semiotika. Penulisnya mengeksplorasi yang dilakukan Arkoun terhadap persoalan bahasa dengan persoalan agama dan masyarakat. ${ }^{10}$ Kedua, Angelo Mazzocco, Linguistic Theories in Dante and the Humanists: Studies of Language and Intellectual History in Late Medieval and Early Renaissance Italy, tahun 1993. ${ }^{11}$ Ketiga, artikel jurnal History and Theory, berjudul $A$ Bedrock of Order: Hayden White's Linguistic Humanism yang ditulis Hans Kellner. ${ }^{12}$ Dalam retorika, gaya argumen, peran penulis, dan subjek itu sendiri, "meta-histori" tampaknya mendominasi dan mengontrol setiap wacana. Artikel ini berisi ulasan tentang buku Metabistory: The Historical Imaginationin Nineteenth-Century Europe, yang subjeknya adalah sejarawan, alurnya bersifat diakronik, namun secara khusus membahas kritik sastra, filsafat, dan sejarah. Keempat, buku berjudul Linguistic Content: New Essays on the History of Philosophy of Language, karya Margaret Cameron dan Robert J. Stainton, tahun $2015,{ }^{13}$ dijelaskan dalam salah satu bab buku ini berfokus pada pandangan Lorenzo Valla, seorang humanis Renaisans. Ia memberikan karakterisasi yang cukup luas dari pendekatan humanis terhadap bahasa dan makna. Valla juga membandingkan berbagai gerakan kontemporer dalam filsafat bahasa, namun ia juga cukup hati-hati merekam poin-poin yang menjadi pembanding. Bagi Valla, adalah kebiasaan linguistik yang mendasari makna: penggunaan linguistik harus seiring dengan aturan tata bahasa dan kosakata. Menurutnya, pembelajaran linguistik bersifat praktis, bukan teoretis dan dengan demikian hal tersebut merepresentasikan sebuah gerakan menuju penggunaan bahasa sosial, pragmatis. Kelima, jurnal yang ditulis Sarah Stever Gravelle, "The Latin-Vernacular Question and Humanist Theoryof Language and Culture," Journal of the History of Ideas. ${ }^{14}$ Studi yang dilakukan Sarah ini berusaha memperdalam pemahaman tentang kontribusi kaum humanis Quattrocento terhadap filsafat bahasa. Memang kontribusi tersebut secara umum diakui, tetapi diperlukan lebih banyak bukti dan pemaparan dari sumber selain Valla. ${ }^{15}$

${ }^{10}$ Baidhowi, Antropologi Al-Qur'an (Yogyakarta: PT. LKiS Pelangi Aksara, 2009). 21.

11 Angelo Mazzocco, Linguistic Theories in Dante and the Humanists: Studies of Language and Intellectual History in Late Medieval and Early Renaissance Italy (Leiden, New York, Kol: BRILL, 1993).

${ }^{12}$ Hans Kellner, "History and Theory," A Bedrock of Order: Hayden White's Linguistic Humanism 19 (December 1980).

${ }^{13}$ Margaret Cameron and Robert J. Stainton, Linguistic Content: New Essays on the History of Philosophy of Language (Oxford University Press, 2015).

14 Sarah Stever Gravelle, "The Latin-Vernacular Question and Humanist Theory of Language and Culture," Journal of the History of Ideas 49, no. 3 (1988): 367-86, https://doi.org/10.2307/2709483.

15 Lihat Salvatore Camporeale, Lorenzo Valla: Umanesimo e Teologia (Florence, 1972).Hanna-Barbara Gerl, Rhetorik Als Philosophie: Lorenzo Valla (Munich, 1974).Charles 
Beberapa humanis lainnya berbagi pemahamannya bahwa terjadinya perbedaan linguistik dikarenakan oleh perbedaan karakter dan pikiran budaya. Seperti Valla, para humanis ini menggunakan studi perbandingan bahasa untuk membangun hubungan bahasa, budaya dan mentalitas. Dua studi perbandingan sangat berguna untuk teori bahasa humanistik. Salah satunya adalah bahasa Latin dan Yunani. Studi terakhir ini menimbulkan munculnya refleksi pada perubahan linguistik dalam budaya dan signifikansinya dalam sejarah intelektual. Kelima, buku berjudul Routledge Advances in Communication and Linguistic Theory: Critical Humanist Perspectives: The Integrational Turn in Philosophy of Language and Communication yang diedit oleh Adrian Pablé, tahun 2017. ${ }^{16}$ Buku ini adalah kumpulan refleksi ilmiah tentang tema humanisme dari perspektif linguistik integrasional (integrational linguistic perspective). Ini mempelajari pemikiran humanis dalam kaitannya dengan filsafat bahasa dan komunikasi yang mendukungnya dan mempertimbangkan pertanyaan apakah menjadi seorang 'humanis' mengikat seseorang ke suatu pandangan bahasa tertentu. Kontribusi untuk jilid ini mengeksplorasi apakah linguistik integrasional, yang diinformasikan oleh semiologi non-mainstream dan mengadopsi perspektif linguistik awam, mampu menawarkan jawaban lebih baik untuk pertanyaan ontologis dan epistemologis ketika'berdebat' mengenai proyek humanis-pertanyaan yang berkaitan dengan diri, alasan, keaslian, kreativitas, agensigratis, pengetahuan dan komunikasi manusia. Perspektif humanis yang diadopsi oleh para kontributor untuk volume ini sangat penting sejauh mereka mulai dari asumsi semiologis yang menantang gagasan yang diterima dalam linguistik arus utama, seperti keyakinan bahwa bahasa adalah kode-tetap dari beberapa jenis, komunikasi yang melayani tujuan pemindahan pikiran, dan bahwa bahasa adalah prasyarat untukkomunikasi. Keenam, disertasi berjudul Hasyizah al-Khudhari 'ala Syarb Ibn 'Aqil 'ala Alfiyyah Ibn Malik oleh Athiyyah Hazrasyi. Disertasi ini menjelaskan tentang komentarkomentar al-Khudhari atas nadz̧am Alfiyyah Ibn Malik. ${ }^{17}$

Sebab itu, sebagai salah satu upaya mengembangkan argumentasi Halliday di atas dan sebagai satu di antara upaya mengembangkan kefitrahan ide yang dimiliki manusia untuk melakukan eksplorasi atas materi-materi kebahasaan atau kaidah-kaidah bahasa Arab, yang salah satunya disebabkan oleh 'kejenuhan'

Trinkaus, In Our Image and Likeness: Humanity and Divinity in Italian Humanist Thought, vol. I (Chicago, 1970). 71-103;Lisa Jardine, "Lorenzo Valla and the Origins of Humanist Dialectic," Journal of the History of Philosophy XV (1977). 64-143. Lihat juga Nancy Strueve, The Language of History in the Renaissance: Rhetoric and Historical Consciousness in Florentine Humanism (Princeton, 1966).Jerrold Seigel, Rhetoric and Philosophy in Renaissance Humanism: The Union of Eloquence and Wisdom, Petrarch to Valla (Princeton, 1966).Thomas Greene, The Light from Troy: Imitation and Discovery in Renaissance Poetry (New Haven, 1982).Richard Waswo, Language and Meaning in the Renaissance (Princeton, 1987).

${ }^{16}$ Adrian Pablé, Critical Humanist Perspectives: The Integrational Turn in Philosophy of Language and Communication (New York: Routledge, 2017).

${ }^{17}$ 'Athiyyah Hazrasyi, "Hasyiyah al-Khudhari 'ala Syarh Ibn 'Aqil 'ala Alfiyyah Ibn Malik" (Disertasi, Universitas Al Jazair, 2016). 
yang memadati benaknya dengan kaidah-kaidah 'dogmatik' yang berkutat pada hafalan dan sebagainya, tanpa penelusuran lebih kekinian, maka pertanyaan yang muncul adalah apakah tafsiran humanistik terhadap kaidah-kaidah bahasa Arab mampu melandingkan teks-teks kaidah kebahasaan ke dalam situasi kekinian?

\section{Hasil dan Pembahasan}

Sudah saatnya untuk melihat kaidah-kaidah bahasa Arab dalam perspektif yang berbeda. Terlebih, bahasa sebagai media komunikasi. Dalam penciptaan kaidahnya pun terjadi melalui proses kreasi para ahli. Sejalan dengan inilah, makna suatu kaidah kebahasaan ditangkap dengan benak kreatif pula. Memang, berdiri di atas tapal batas antara 'kemapanan' dan 'pemberontakan' pemaknaan atas suatu kaidah kebahasaan cukup 'rawan'. Oleh karena itu, pemaknaan humanistik yang polisemantik ${ }^{18}$ terhadap kaidah bahasa Arab terjadi karena makna terkandung di dalamnya berkaitan dengan apa yang dijelaskan Warsiman dalam Membumikan Pembelajaran Sastra yang Humanis bahwa secara kelaziman, makna tercantum dalam bahasa yang dimilikinya. Selain itu,makna memiliki kaitan dengan bagian luar bahasa, yakni kenyataan-kenyataan dalam kehidupan dan situasi sosial dan budaya. Lebih lanjut, Warsiman menjelaskan bahwa makna juga dapat muncul yang disebabkan pertalian konteks teks di dalamnya. Dan, makna memiliki pertalian dengan rujukan (referensi) dan rancangan ide penafsirnya. ${ }^{19}$

Misalnya, untuk konteks ini, nahwu sebagai objek pemikiran. Pijakan dasarnya adalah bahwa naluriah nahwu tidak dapat dipisahkan dengan metode berpikir yang mengandalkan penalaran sebagai basisnya. Bila filsafat sebagai 'mukjizat' bagi Yunani, sementara kaidah bahasa Arab sebagai 'mukjizat bagi bangsa Arab, maka bila kedua pengetahuan ini menyatu maka akan menghasilkan suatu pengetahuan baru yang berbeda. Sebab itu, kaidah tata bahasa Arab mesti bersinergi dengan filsafat. Kolaborasi ini melahirkan pengetahuan yang sebelumnya tidak ada menjadi ada. Bila demikian, hemat

${ }_{18}$ Arti sentral dari kata poli-semantik akan menjadi satu dari mana makna turunan dapat dihasilkan dengan (paling sedikit) usaha-usaha kognitif. Ahli bahasa Caramazza dan Grouber telah menemukan ketergantungan antara tingkat pengembangan polisemi leksem dan tingkat keabstrakan makna intinya: "Makna inti akan bervariasi dalam tingkat keabstrakan, yang pada dasarnya ditentukan oleh sejauh mana mereka mengizinkan polisemi; semakin polisemik, semakin abstrak representasi. Sebaliknya, sementara semakin kurang polisemik, semakin kurang abstrak representasi." Lihat Caramazza A and Grober E, Polysemy and the Structure of the Subjective Lexicon (Washington, 1976). 181-206. Ciri khas bahasa alami dengan poli-semantik dan implikasi metafora sangat sering menjadi penghalang komunikasi yang sukses. Kesulitannya adalah tentang ketidakmungkinan menggunakan semua kekayaan semantik dan kebutuhan konstan untuk memilih komponen makna yang paling substansial dari sebuah kata polisemantik. Svetlana Pesinaa and Lyalya Gainullovna Yusupovab, "Words Functioning in Lexicon," 2015. 43.

${ }^{19}$ Warsiman, Membumikan Pembelajaran Sastra yang Humanis (Malang: Universitas Brawijaya Press, 2016). 92. 
penulis, harus ada 'peleburan' antara nahwu dan filsafat agar kedua disiplin ilmu tersebut mampu saling memberikan pengaruhnya sehingga membuahkan pengetahuan berbeda, baru dan segar. Nahwu sebagai bagian dari suatu perkembangan peradaban Islam harus merangkul kebudayaan, bahasa dan filsafat kelompok lain. Oleh Hanafi, Islam menjadi penerus bagi masa Yunani Kuno, bagi filsafat Yunani. ${ }^{20}$ Itu kenapa linguistik humanistik ${ }^{21}$ sangat memperhatikan lebih dari sekadar tata bahasa dan teori tata bahasa. ${ }^{22}$ Sejalan dengan pernyataan ini, George Lakoff ${ }^{23}$ berpendapat bahwa ada sejumlah bidang-bidang yang menjadi bagian dari linguistik humanistik; struktur kognitif dan interaksi kepribadian. Yang dimaksud nilai-nilai kemanusiaan disini yaitu upaya memahami kaidah-kaidah bahasa Arab yang terdapat di dalamnya nilainilai kemanusiaan, seperti kesetaraan. Kesetaraan dalam hak (al-musawah fi albuquq), kesetaraan dalam kondisi (al-musawah fi al-dzhuruf) dan kesetaraan dalam genetik biologis (al-musawah fi al-mauruts al-biyuluji), dan secara umum warisan sifat manusiawi. Yang terakhir adalah inti dari pertanyaan tentang realitas, dan hal ini masuk ke ranah bidang ilmu alam dan dapat dikaji melalui penelitian yang

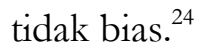

\footnotetext{
${ }^{20}$ Hasan Hanafi, Islam dan Humanisme: Aktualisasi Humanisme Islam di Tengah Krisis Humanisme Universal (Yogyakarta: Pustaka Pelajar, 2007). 190.

${ }^{21}$ Humanistik di sini, bukan humanistik sebagai suatu paham, tetapi lebih kepada nilainilai pragmatis dalam kaidah bahasa Arab. Humanistik menitikberatkan kepada sudut sifat yang melekat pada suatu kata itu sendiri. Nilai-nilai yang termuat dalam kaidah-kaidah bahasa Arab sebagai bentuk semangat dalam membudayakan manusia atau memanusiakan manusia. Aspekaspek kemanusiaan (humanisitik) yang berkooperatif dengan kaidah-kaidah bahasa Arab menelurkan pernyataan-pernyataan kalimat yang begitu indah dan santun. Yang menjadi stressing dalam nilai-nilai kemanusiaan di antaranya adalah menjamin kesinambungan keberadaan manusia. Dalam pengertian lain, titik tekannya adalah memanusiakan manusia agar lebih manusiawi dan berperilaku yang berbudaya serta berkepribadian yang siap untuk berkembang.Hal ini tercermin ketika seseorang melakukan persinggungan (ibtikak) dengan situasidi luarnya maka tanggapan benaknya tidak jauh dari anasir subjektif dalam dirinya.Tentu saja, pengalamannya akan memenuhi benaknya dalam mengeksplorasi objek-objek yang ditemuinya, termasuk didalamnya adalah kaidah-kaidah bahasa Arab. Humanisme bagian dari filsafat, dan tidak selalu mengkajinya mengerucut kedalam dimensi teologis. Filsafat dalam kajiannya juga merambah-selain teologis- kepada kosmologi dan antropologi. Tidak ada wilayah yang dianggap sakral untuk tidak mungkin dikaji, semuanya berasas profan yang wilayah liputannya adalah alam dan manusia.

${ }^{22}$ George Lakoff, Humanistic Linguistics (Berkeley: University of California, 1974). 1.

${ }^{23}$ Lihat Philipp Strazny, Encyclopedia of Linguistics: A-L (Fitzroy Dearborn Publishers, Incorporated, 2005). Awal tahun 1986, George Lakoff, sebagai seorang profesor linguistik di University of California di Berkely. Lihat Frederick Stecker, Podium, the Pulpit, and the Republicans, The: How Presidential Candidates Use Religious Language in American Political Debate: How Presidential Candidates Use Religious Language in American Political Debate (Santa Barbara: ABC-CLIO, 2011).xvii.
}

${ }^{24}$ Noam Chomsky, Gharizah al-Hurriyyab: Maqalat fi al-Falsafah wa al-Fawdhawiyyah wa alThabi'iyyah al-Basyariyyah (Mamdouh Adwan Publishing, 2017). 43. 
Kekhasan yang dimiliki bahasa Arab, antara lain adalah kesaksian batin (budhur bathini) dalam ego yang terjaga. Ketika ego yang arif melakukan proses berpikirnya, maka ia akan merumuskan kalimat dalam bahasa Arab. Kemunculan ego posisif yang berpikir terdapat dalam kejiwaan internal yang teraplikasi dalam pronomina-pronomina (dhama ir ) dan kata kerja-kata kerja (af'al) yang terbangun dalam bangunan kata. Karena itu, kata kerja yang 'bekerja', maknanya tidak independen tanpa pelibatan ego. Sementara itu, zat di dalamnya berkaitan dengan kata kerja dalam susunan asalnya, contohnya kata (أفكر، أكتب).

Sementara itu, sejumlah bahasa-bahasa lain, lazimnya dalam setiap konteks, ada egoisme lewat pronomina pertama (dhamir mutakallim), pronomina kedua (mukhathab) atau pronomina ketiga (gha ib) secara gamblang, yang pada gilirannya relasi kata kerja dan pelaku (fa'i), tanpa kegamblangan tersebut, tidak dapat dipahami. Sekadar contoh, (أنا أفكر). Dalam bahasa Arab, Anda cukup mengatakan (أفكر), tanpa perlu menetapkan dhamir mutakallim atau mukhathab atau gha ib dalam setiap konteks. ${ }^{26}$ Dalam kaitan ini, misalnya, dalam bait Alfiyyah Ibn Malik ${ }^{27}$ tercatat sebagai berikut:

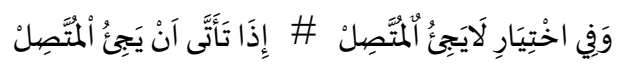

Atau misalnya, bait lain:

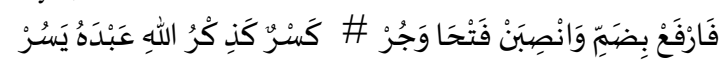

${ }^{25}$ Usman Amin, Falsafah al-Lughah al-'Arabiyyah, (Bandung: PSIBA Press, 2008). 27-28.

${ }^{26}$ Amin. 28.

${ }^{27}$ Ibnu Malik memiliki nama lengkap Muhammad Jamal ad-Din ibn 'Abd Allah ibn Malikal-Thayy, lahir di Jayyan. Teori-teori nahwu yang dihasilkannya mencerminkan aliran teori gramatika Arab Andalusia. Karya-karyanya banyak ditulis dalam bentuk nadz̧am (kumpulan syair). Untuk menguatkan teorinya, ia senantiasa mengambil dalil penguat (syabid) yang bersumber dari ayat al-Qur'an atau berasal dari hadits. Ketika sumber penguat atas argumentasinya tidak terdapat dalam keduanya, ia adopsi dari syair-syair Arab terkenal, yang seluruh hasil ide-ide kenahwuannya ia ekspresikan ke dalam narasi-narasi puitik berbentuk nad₹hamatau juga prosa (natsr). Karya Ibnu Malik ini banyak dikaji di pesantren-pesantren di Indonesia, terutama pesantren yang memfokuskan kepada penguasaan kitab-kitab kuning. Van Bruinessen mencatat bahwa kitab-kitab klasik (baca: kitab kuning) yang diidentikkan dengan pesantren sebagai institusi pendidikan Islam tertua telah ada jauh sebelum pesantren berdiri. Kendati secara historis, pesantren baru berdiri di Indonesia pada abad ke-18 M, namun kitabkitab klasik telah dipelajari orang sejak abad ke-16 M. Sejumlah karya-karya dialihbahasakan ke dalam bahasa Melayu dan Jawa, dan beberapa penulis Indonesia telah menulis kitab berbahasa Arab dengan gaya dan isi yang mirip dengan kitab-kitab ortodoks. Martin van Bruinessen, Kitab Kuning, Pesantren Dan Tarekat; Tradisi-Tradisi Islam Di Indonesia, III (Bandung: Mizan, 1999). 27. Kitab yang ditulis Ibnu Malik banyak disyarah oleh banyak kalangan ulama, di antaranya Ibnu Hisyam al-Anshari (709-761 H/1309-1360 M) dalam Audhah Masalik Ila Alfiyah Ibni Malik, Mughni al-Labib 'an Kutub al-A'arib, Syarb Syudzur al-Dzabab fi Ma'rifati Kalam al-'Arab, Quthr alNada wa Ball al-Sada, Ibnu 'Aqil (694-769 H/1294-1367 M) dengan judul Syarah Ibn 'Aqil 'ala Alfiyyah. Raghib As-Sirjani, Sumbangan Peradaban Islam pada Dunia (Jakarta: Pustaka Al Kautsar, 2012). 409-410. 


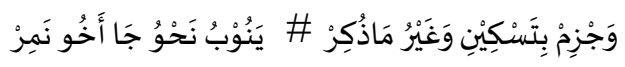

Rafa'kanlab dengan harakat dammah, dan nashabkanlab dengan barakat fathah, serta jerkanlah dengan harakat kasrah seperti dalam lafal ذِكْرُ اللهِ عَبْدَهُ (يَسُرن). Bacalah jarm dengan sukun, dan ada pengganti selain yang sudah جَاءُ أَخُو نَمِرب dijelaskan seperti kalimat

Bangunan relasi antar sesama dilandasi dengan kekompakan (ضمّ), keterbukaan (فتحا), menghindari faktor-faktor pemicu perpecahan (جر), menghidupkan relasi spiritual vertikal (ذكر الله), ketegaran dalam menjalani kehidupan (استقم)).

Pemaknaan ini muncul dari apa yang didengar dan dilihat oleh pembacanya terhadap teks-teks kebahasaan Arab, di mana aturan gramatik nahwu $^{28}$ - di samping ilmu nahwu (grammar) sebagai balancing bagi bahasa Arab (mizan al-lughah al-'arabiyyah) $^{29}$ dan sharf (kebiasaan-kebiasaan linguistik) memberikan kepada masyarakat pilihan-pilihan tertentu untuk menginterpretasikan makna yang dilihat dan didengarnya. ${ }^{30}$

Kebahasaan yang humanistik merupakan nurani bahasa. Tidak ada kebohongan dalam suatu bahasa, meski pikiran melakukan pemberontakan. Kefitrahanlah yang mendorong manusia menggunakan bahasanya. Bahasa kemanusiaan akan terkikis keasliannya bila searah dengan dinamika manusia yang terdampak oleh situasi dan kondisi yang melingkarinya. Bahasa kemanusiaan hilang oleh keterpengaruhan lingkungan, televisi, dan media-media lainnya. Sebab itu, sebagai warga yang hidup berhak melindungi kefitrahannya dan mengembangkan kefitrahannya secara sadar. Bahasa berbasis kemanusiaan merupakan bahasa jiwa. Pasalnya, setiap jiwa lahir secara fitrah. ${ }^{31}$

\footnotetext{
${ }^{28}$ Empat dasar linguistik Arab yang terintegrasi dengan ilmu nahwu yang diungkapkan Ibnu Khaldun, yaitu ilmu nahwu, ilmu bahasa, ilmu sastra, dan ilmu bayan. Ibnu Khaldun, alMuqaddimah, Maktabah Syamilah v.2.11, 352.

${ }^{29}$ Usman Amin, Falsafah al-Lughah al- 'Arabiyyah, trans. oleh Wagino Hamid Hamdani (Bandung: PSIBA Press, 2008). 4-5. 1987). 62 .

${ }^{30}$ Hudson, 'Ilm al-Lughah al-Ijtima'iy (Baghdad: Dar al-Syu'un al-Tsaqafiyyah al-'Amah,

${ }^{31}$ Fitrah - menurut Ahmad bin Ibnu Faris (w. 359 H) - secara bahasa berarti membuka sesuatu dan menampakkan (fath al-syai' wa ibrazubu). Lihat Ahmad bin Faris, Maqayis al-Lughab (Kairo: Dar Ihya' al-Kutub al-'Arabiyyah, 1366). 217. Lihat Jar Allah Mahmud bin 'Umar AlZamakhshari, Asas al-Balaghah (Beirut-Lebanon: Dar al-Fikr, 2000). Ismail bin Hammad alJawhari $(393 \mathrm{H})$ juga mengartikan fitrah dengan 'membuka'. Isma'il bin Hammad Al-Jawhari, alShibhah Taj al-Lughab wa Shibhah al-'Arabiyyah, vol. 2 (Beirut: Dar al-'Ilm li al-Malayin, n.d.). 781. Sementara menurut Hikmet Fayyad, fitrah berarti awal, penemuan dan penciptaan. Fitrah merupakan naluri kekuatan yang Tuhan simpankan ke dalam diri manusia dan Tuhan kreasikan fitrah itu kepada manusia sehingga mampu mendorong manusia untuk tetap menuju kepada Tuhannya melalui nilai-nilai dan etika-etika serta budi-budi luhur lainnya. Hikmet Fayyad Hussein Kazem, al-Fithrah fi al-Islam (Dar al-Kutub al-'Ilmiyyah, 2008). 18-20.
} 
Sebagai salah satu upaya mengembangkan kefitrahan ide yang dimiliki manusia, ada upaya-upaya eksplorasiatasmateri-materi kebahasaan atau kaidahkaidah bahasa Arab, yang salah satunya disebabkan oleh 'kejenuhan' yang memadati benaknya dengan kaidah-kaidah 'dogmatik' yang berkutat pada hafalan dan sebagainya, tanpa penelusuran lebih kekinian. Oleh sebab itu, tafsiran humanistik terhadap kaidah-kaidah bahasa Arab bertujuan melandingkan teks-teks kaidah kebahasaan kedalam situasi kekinian.

Oleh karena itu, bahasa dan pikiran merupakan dua unsur yang saling terkait yang satu sama lain saling terpengaruh dan mempengaruhi. Sebab itu, bahasa tidak terlepas dari pikiran, dan bukan hanya sebagai wadah semata. ${ }^{32}$ Bahasa Arab sebagai sarana ekspresif tentang manusia dan konsepsinya terhadap semesta yang mampu mendialektikan dan menginteraksikan antara bahasa dan manusia, sekaligus juga mampu menginternalisasi manusia kedalam bahasa dan sistemnya. Bahasa pun mampu mengungkapkan sejumlah ilmu kemanusiaan yang sifatnya teoretis dan terapan. Hal ini dipengaruhi oleh bagaimana suatu bahasa beradaptasi dengan suatu ilmu. Yang pada gilirannya melahirkan pengetahuan yang sebelumnya belum ada, kemudian menjadi diadakan. ${ }^{33}$

Yang menjadi argumentasi lain adalah bahasa Arab yang merupakan bahasa yang diekspresikan manusia, juga merupakan hasil budaya bangsa Arab itu sendiri. Al-Qur'an saja yang juga berbahasa Arab dapat ditafsirkan dan menghasilkan tafsiran-tafsiran yang multi pandangan, terlebih selain bahasa alQur'an (baca: bahasa Arab), sebab bukan bahasa malaikat, apalagi bahasa Tuhan. ${ }^{34}$ Bahasa Arab memiliki aspek linguistik, pragmatik, atau juga sosio-

\footnotetext{
32Hatim 'Alwi Al-Tha'i, "Nasy'ah al-Lughah wa Ahammiyyatuha" 9 (2009). 211.

${ }^{33}$ Ini memang merupakan sebuah perubahan. Perubahan yang demikian oleh Kuhn disebut perubahan ilmu pengetahuan yang dilewati melalui jenjang kemajuan ilmu yang disebabkan terjadinya penghimpunan pengetahuan yang belum ada sebelumnya dan kemudian diikuti jenjang selanjutnya dengan ditandai perubahan ilmu pengetahuan yang disebabkan terjadinya pergeseran secara fundamental yang oleh Kuhn dinamai revolusi keilmuan. Dalam kondisi yang berbeda, ilmu terkuasai oleh paradigma tertentu. Atas kondisi itulah kemudian akumulasi ilmu pengetahuan mencapai suatu titik puncak sehingga kemajuan ilmu tidak dapat terbendung lagi, dan untuk indikator atas situasi ini munculnya karya-karya ilmiah yang bertebaran. Namun, kendati berseliwerannya karya-karya ilmiah dapat mengakumulasikan berbagai ilmu pengetahuan menurut paradigma yang telah eksis, juga berdampak pada terjadinya penyelewengan-penyelewengan yang tidak mampu diurai mengandalkan paradigma yang sudah mapan. Kondisi anomali ini akan berlanjut kepada suatu kondisi di mana penyelewenganpenyelewengan melampaui pada garis titik ujungnya. Kalau krisis sudah memuncak, akan terjadilah revolusi ilmiah yang ditandai dengan paradigma lama ditinggalkan dan muncul paradigma baru yang akan digunakan untuk landasan baru bagi gagasan-gagasanilmiah. Lihat JJ Ihalauw, Konstruksi Teori: Komponen Dan Proses (Jakarta: Grasindo, 2008). 139.

${ }^{34}$ Bahasa Arab memang dikenal sebagai bahasa yang memiliki berbagai macam tanda kelengkapan (baca: atribut). Terlebih, sebagai bahasa kitab suci, bahasa Arab merupakan bahasa agama bagi kaum muslim, di samping sebagai bahasa nasional yang digunakan para penuturnya di kawasan Timur Tengah, lebih dari dua puluh dua negera menggunakannya. Perserikatan Bangsa-bangsa (PBB) juga mengakui bahasa Arab sebagai bahasa resminya. Selain itu semua,
} 
kultural, dan bahkan aspek humanistik, sebagai sub sistem budaya dan hasil budaya. Oleh karena itu, pada kenyataannya, bahasa Arab patuh dan mengikuti aturan linguistik yang sudah disepakati oleh para pengucapnya, di mana aturan itu meliputi aspek morfologi, sintaksis, fonologi, leksikologi dan semantis. Dengan demikian, bahasa Arab menjadi suatu sub sistem sosial budaya yang tidak menutup dirinya untuk dilakukan uji kritis dan dikembangkan melalui studi-studi interdisipliner. Pendapat ini mengisyaratkan bahwa bahasa Arab adalah sebuah sistem sosial-budaya yang terbuka untuk dikaji, dikritisi dan dikembangkan. ${ }^{35}$

\section{Penutup}

Upaya memaknai kebahasaan Arab yang dikorelasikan dengan nilai-nilai kemanusiaan dapat memberikan kontribusi tentang cara berpikir kebahasaan guna mengawal keberlangsungan bahasa Arab itu sendiri. Selain itu, pada sisi lain, membangun ilmu humanistik yang sebagai general science yang menjadi dasar bagi ilmu-ilmu lainnya.

Pikiran tidak sekadar wadah bahasa. Lebih dari itu, pikiran mampu mendialektikan bahasa dan manusianya, sehingga keindahan antara ekspresi kebahasaan dan kemanusiaan yang terjalin harmonis memunculkan pengetahuan baru yang segaris lurus dengan kedinamisan manusia itu sendiri sebagai makhluk interpretator dalam konteks zamannya.

bahasa Arab disebut juga lughah al-dhad dan sekaligus sebagai bahasa warisan sosial budaya (lughah at-turats al-ijtima"i al-tsaqafi .Ubaid Ridlo, "Bahasa Arab Dalam Pusaran Arus Globalisasi: Antara Pesismisme dan Optimisme," Ihyaul 'A rabiyyah 2 (2015). 211. Lihat juga Muhbib Abdul Wahab, Epistemologi Dan Metodologi Pembelajaran Bahasa Arab Jakarta (Jakarta: UIN Press, 2008).Dengan mengutip Jabir Qumaihah, Ubaid menjelaskanbahwa karena penggunaan bahasa Arab dianggap sebagai wadah ekspresi al-Qur an, maka eksistensi bahasa Arab diberikan proteksi dari Tuhan (al-himayah al-ilabiyyah) dan terjamin keberadaannya. Maka itulah, tak heran bila bahasa Arab tidak mengalami fase-fase penuaan dan kemurniannya dapat dipertanggungjawabkan. ${ }^{34}$ Lihat juga Ibn Faris, al-Shabibi fi Figh al-Lughah wa Sunan al-Arab fi Kalamiha (Beirut: Muassasah Badran, 1963).16.

${ }^{35}$ Lihat Ibn Faris, al-Shabibi fi Figh al-Lughab wa Sunan al-'Arab fi Kalamiba (Beirut: Muassasah Badran, 1963). 16. 


\section{Bibliografi}

A, Caramazza, and Grober E. Polysemy and the Structure of the Subjective Lexicon. Washington, 1976.

Al-Jawhari, Isma'il bin Hammad. al-Shibhah Taj al-Lughah wa Shibhah al'Arabiyyah. Vol. 2. Beirut: Dar al-'Ilm li al-Malayin, n.d.

Al-Khuli, Muhammad 'Ali. Qawa id Tabwiliyyah li al-Lughah al-'Arabiyyah. Yordan: Dar al-Falah, 1999.

Al-Masmudi, Mushthafa. al-Nidð̧ham al-'Alami al-Jadid. Kuwait: Silsilah 'Alam alMa'rifah, 1985.

Al-Tha'i, Hatim 'Alwi. "Nash'ah al-Lughah wa Ahammiyyatuha" 9 (2009).

Al-Zamakhshari, Jar Allah Mahmud bin 'Umar. Asas al-Balaghah. BeirutLebanon: Dar al-Fikr, 2000.

Amin, Usman. Falsafah al-Lughah al-'A rabiyyah. Bandung: PSIBA Press, 2008.

As-Sirjani, Raghib. Sumbangan Peradaban Islam pada Dunia. Jakarta: Pustaka Al Kautsar, 2012.

Baidhowi. Antropologi Al-Qur'an. Yogyakarta: PT. LKiS Pelangi Aksara, 2009.

Bruinessen, Martin van. Kitab Kuning, Pesantren dan Tarekat; Tradisi-Tradisi Islam di Indonesia. III. Bandung: Mizan, 1999.

Cameron, Margaret, and Robert J. Stainton. Linguistic Content: New Essays on the History of Philosophy of Language. Oxford University Press, 2015.

Camporeale, Salvatore. Lorenzo V alla: Umanesimo e Teologia. Florence, 1972.

Chomsky, Noam. Gharizah al-Hurriyyah: Maqalat fi al-Falsafah wa al-Fawdhawiyyah wa al-Thabi'iyyah al-Bashariyyah. Mamdouh Adwan Publishing, 2017.

Dzhahir, 'Umar. Ta'ammulat fi Falsafah al-Lughah; Khushushiyyah al-Lughah al'Arabiyyah wa Imkanatuha. Beirut: Dar al-Rafidhain, 2008.

Faris, Ahmad bin. Maqayis Al-Lughah. Vol. 2. Kairo: Dar Ihya' al-Kutub al'Arabiyyah, 1366.

Faris, Ibn. al-Shabibi fi Figh al-Lughah wa Sunan al-'Arab fi Kalamiha. Beirut: Muassasah Badran, 1963.

Gerl, Hanna-Barbara. Rhetorik Als Philosophie: Lorenzo V alla. Munich, 1974.

Gravelle, Sarah Stever. "The Latin-Vernacular Question and Humanist Theory of Language and Culture." Journal of the History of Ideas 49, no. 3 (1988): 367-86. https://doi.org/10.2307/2709483.

Greene, Thomas. The Light from Troy: Imitation and Discovery in Renaissance Poetry. New Haven, 1982. 
Hanafi, Hasan. Islam dan Humanisme: Aktualisasi Humanisme Islam di Tengah Krisis Humanisme Universal. Yogyakarta: Pustaka Pelajar, 2007.

Hazrashi, 'Athiyyah. "Hasyiyah Al-Khudhari 'ala Syarh Ibn 'Aqil 'ala Alfiyyah Ibn Malik.” Disertasi, Universitas Al Jazair, 2016.

Ihalauw, JJ. Konstruksi Teori: Komponen Dan Proses. Jakarta: Grasindo, 2008.

Jardine, Lisa. "Lorenzo Valla and the Origins of Humanist Dialectic." Journal of the History of Philosophy XV (1977).

Kazem, Hikmet Fayyad Hussein. al-Fithrah fi al-Islam. Dar al-Kutub al-'Ilmiyyah, 2008.

Kellner, Hans. "History and Theory." A Bedrock of Order: Hayden White's Linguistic Humanism 19 (December 1980).

Kotob, Islam. Majallah Majma' al-Lughah al-'A rabiyyah. Kairo: IslamKotob, 2003.

Lakoff, George. Humanistic Linguistics. Berkeley: University of California, 1974.

Mazzocco, Angelo. Linguistic Theories in Dante and the Humanists: Studies of Language and Intellectual History in Late Medieval and Early Renaissance Italy. Leiden, New York, Kol: BRILL, 1993.

Monib, Mohammad, and Islah Bahrawi. Islam \& Hak Asasi Manusia Dalam Pandangan Nurcholish Madjid. Jakarta: Gramedia Pustaka Utama, 2011.

Oro, Slevan, Gad Dishan, and Gamal Kologli. Falsafah Al-Lughah. Beirut: Presses Universitaires de France, 2004.

Pablé, Adrian. Critical Humanist Perspectives: The Integrational Turn in Pbilosopby of Language and Communication. New York: Routledge, 2017.

Pesinaa, Svetlana, and Lyalya Gainullovna Yusupovab. "Words Functioning in Lexicon," 2015.

Richards, CJ, and ST Rodgers. Approaches and Methods in Language Teaching. Cambridge: Cambridge University Press, 2001.

Ridlo, Ubaid. "Bahasa Arab Dalam Pusaran Arus Globalisasi: Antara Pesismisme Dan Optimisme.” Ibyaul 'A rabiyyah 2 (2015).

Seigel, Jerrold. Rhetoric and Philosophy in Renaissance Humanism: The Union of Eloquence and Wisdom, Petrarch to V alla. Princeton, 1966.

Solikhah, Imroatus. "Paradigma Baru Pembelajaran Bahasa Dan Resistensi Masyarakat Terhadap Perubahan." Cendekia 8, no. 2 (October 2014).

Stecker, Frederick. Podium, the Pulpit, and the Republicans, The: How Presidential Candidates Use Religious Language in American Political Debate: How Presidential Candidates Use Religious Language in American Political Debate. Santa Barbara: 
ABC-CLIO, 2011.

Strazny, Philipp. Encyclopedia of Linguistics: A-L. Fitzroy Dearborn Publishers, Incorporated, 2005.

Strueve, Nancy. The Language of History in the Renaissance: Rhetoric and Historical Consciousness in Florentine Humanism. Princeton, 1966.

Tjaya, Thomas Hidya. Humanisme dan Skolastisisme, Sebuah Debat. Yogyakarta: Kanisius, 2004.

Trinkaus, Charles. In Our Image and Likeness: Humanity and Divinity in Italian Humanist Thought. Vol. I. Chicago, 1970.

Wahab, Muhbib Abdul. Epistemologi dan Metodologi Pembelajaran Bahasa Arab Jakarta. Jakarta: UIN Press, 2008.

Warsiman. Membumikan Pembelajaran Sastra yang Humanis. Malang: Universitas Brawijaya Press, 2016.

Waswo, Richard. Language and Meaning in the Renaissance. Princeton, 1987.

Yahya, Iip D. Gus Dur: Berbeda itu Asyik. Yogyakarta: Kanisius, 2004. 
314 | Arabiyatuna : Jurnal Bahasa Arab, Vol. 3, No. 2, 2019 